\title{
The Obstacles to the Jordanian University Students' Use of the Mobile Phone in University Education
}

\author{
Jebreen A. Hussain ${ }^{1}$ \\ ${ }^{1}$ School of education, Hashemite University, Zarqa', Jordan \\ Correspondence: Jebreen A. Hussain, School of education, Hashemite University, Zarqa', Jordan. E-mail: \\ anasjh@hotmail.com
}

Received: March 7, 2015 Accepted: March 26, 2015 Online Published: May 26, 2015

doi:10.5539/res.v7n7p440 URL: http://dx.doi.org/10.5539/res.v7n7p440

\begin{abstract}
This study aimed at identifying the obstacles that the Jordanian universities' students encounter in using the mobile phone in university education. The study sample consisted of 363 male and female students from Al-Hashmeyah, AL Al-Bayt, and Al Balq'a Applied universities for the academic year 2013-2014. The instrument of the study which was developed by the researcher, consisted of (40) items divided in four domains. The validity and reliability were proven. The results of the study indicated that all the domains and items included in the instrument were main obstacles, it's also indicated that there were significant statistical differences in the domains related to the student attributed to specialization favor of scientific specialization, and it's indicated that there were no significant differences attributed to the experience in using the mobile phone. The study was concluded with some recommendations.
\end{abstract}

Keywords: obstacles, mobile phone, Jordanian Universities

\section{Introduction}

The current period has witnessed a great progress in the fields of knowledge and information technology which resulted in a heavy responsibility falls on the educational institutions to prepare a competent generation to deal with innovations, communication media, multimedia, hyper media, electronic and virtual learning.

The traditional methods of teaching which concentrate on memorizing, and the considering teacher as the center of the educational process, and looking at the book as the primary source of the knowledge are no longer accepted.

Those old traditional methods are no longer able to meet the requirements and the rapid change of this era. The industrial revolution took place in the eighteenth and nineteenth centuries. Then the electronic revolution in the eighteenth of the twentieth century which led to the invention of the computer and its software and satellites. Then the wireless revolution which occurred at the end of twentieth century and the beginning of the twentieth-first century in which the mobile phone and wireless devices came into being (Salem, 2006). The use of a new term in education (mobile learning) came at the beginning of the twentieth-first century. Many researchers used different definitions of mobile learning.

Chen and Kinshuk (2003) defined it as any service or a facilitator tool which provides the learner with the electronic information and the educational content regardless of time and place.

Salem (2006)defined it as the use of micro and manually portable devices such as mobile phones and the personal digital assistants PDAs smart phones and the micro personal computers (Tablet PCs) to achieve flexibility and interactivity in the teaching learning process at any time and any place. Bin Hashim et al. (2010) think that the mobile phone should be designed to provide the instructional materials to the learner and provide wireless communication between learners and teachers.

The idea of the mobile phone was inspired by the use of the radio. The researchers found out that it was possible to develop a new technology to transmit and receive data over a range of frequencies that can be used several times by compressing the data and sending it by units in a very short time to conduct a series of phone calls at the same time (Dahshan \& Younus, 2009). Mobile phone device depend on a set of tools and online services that make them effective communication technologies. These technologies include the following (Bassiouni, 2007). 
1) Using infrared rays for communication. Such rays allow the transfer of data between mobile phone device in a limited distance and about two maters provided direct routing between the two mobile phone devices.

2) Bluetooth: It is a global wireless radio connection. It can be used through the atmosphere for radio communication. Bluetooth has greater extent than infrared rays, and can operate around objects and pass though the material and can have link among several devices at the same time.

3) General Packet Radio System can bring ready and portable internet communication and can provide direct access with the internet address with the stability and transparency of this communication with spending time on preparation of access calls.

4) Wireless Access Protocol (WAP) enables the use of web browser internet for mobile portable terminals and provides the data any way and any time.

5) Short Message Service (SMS) allows mobile users to exchange short text messages with each other; messages should not exceed 160 letters per message.

6) Multimedia Service (MMS) allows the user to send and receive MMS message and exchange text messages, video clips, animations, and colored photos.

Mobile phone technology and software can be used in performing several educational tasks in different roles. The field of mobile learning includes many applications and new frame works for the technology of teaching and learning.

The value which the mobile learning to the educational process includes two aspects: the cognitive aspect represented in the mastery of reading, writing skills, arithmetic and research, and the educational aspects in the changing behavior, acquiring (Dahshan \& Younus, 2009).

With the advent of the mobile learning many research studies were conducted which discussed the impact and the value of the educational and cognitive knowledge provided by mobile learning on the one hand, and on the other hand all the issues concentrated on how mobile learning can achieve and develop reading skills, learning activities in the theories of the theories of the effectives teaching some scholars tried to provide designers with applicable instructions on how and why the mobile learning is more vital in teaching children.

At the same time, another group of researchers took care of measuring the effective mobile learning and its impact on the adult learners in using nontraditional learning and methods such as distance learning and open learning (Hamami, 2006).

All these studies agreed on the impact the digital devices did for learners and teachers. This technology added the element of excitement, joy and vitality on the performance of both sides. Though the learners took more time to master the instruction material, they could achieve participation with each other at the same time. Such technologies gave new vitality to the teaching methods and were a rationale for generation a conviction of a constant change in teaching methods (Salem, 2006).

In spite of the great and rapid progress in the manufacture of the various kinds of the mobile phones device, and in spite of the attempt to overcome their shortcomings, but these devices still suffer from shortcomings which are expected to be tackled in the near future, due to the research and advanced applications of the wireless devices. Besides, mobile learning model is expected to face difficulties during the educational process in reality in the education process.

Salem (2004), Hayes (2004) and Csete, Wong and Vogel (2004) stated that the current generation of the mobile phone devices still suffers from some flaws that may hinder the learning mobile model in some cases, and these defects include:

- The small size of the screen of the mobile phone devices especially the mobile phones and the personal digital devices, which reduces the personal digital devices, which reduces the amount of information they display.

- The storage capacity is limited especially in mobile phones and personal digital devices.

- The life of the batteries is short, so they always require charging, and the data can be lost if there is a fault when charging the battery.

- The large number of different models of the mobile phone devices led to a lack of familiarity with the hardware, especially with the different screen sizes and forms.

- The mobile phone device can be lost or stolen easily more than personal computers.

- Personal computers are stronger than mobile phone devices. 
- The difficulty of using the mobile phone devices for displaying animation (but the third and the fourth generations of the mobile phones facilitate displaying animation).

- The amazing speed change of the mobile phone market which makes mobile phone devices rapidly outdated.

- Teachers and learners need to be trained to use those devices skillfully and efficiently.

- The application of the learning mobile model requires establishing structure such as: wireless networks, and modern equipment.

Some other researchers mentioned difficulties that might hinder the application of this technology in the educational institutions (Dunn, 2012) and (Ganci, 2010):

- The high cost of the smart mobile phone devices and tablet computers where not all students can get them and use them for educational purposes. In addition, the educational institutions need big budgets to obtain such devices and to update them.

- The absence of a specific standard upon which web design and educational multi-media can be built and be compatible with mobile devices and tablet computers, and because of the diversity of these devices and multiple operating system, which makes it difficult to browse these sites and the media correctly.

- Culture: Mobile Learning requires new thinking on the part of teachers, students and educational institutions. This also requires modifying the curriculum to conform with mobile learning as well as the school homework and the roles of the teachers and the student to keep pace with the new development of the learning.

- Adoption of the new development of learning requires the change of the attitudes of all those involved in the educational process as well as accepting mobile learning and adopting positive attitudes towards it meanwhile some educators and students still prefer dealing with the paper, the pen and the textbook in the educational process.

Saleem (2011) added some challenges that hinder the use of mobile learning in education, such as access to the effective mobile learning system, and the problem of protecting the content of the mobile phone devices, in addition to the challenge of the availability of the appropriate hardware for mobile learning as well as storage capacity and the download speed of these devices.

It is clear from the review of the related literature that in spite of the great progress made in the field of the use of the mobile learning technology in education, but its usage in the educational process still encounters many difficulties and obstacles that usually apply to the application of all technologies.

\section{Statement of the Problem}

Today the world is witnessing a huge revolution in the use of the mobile phone application in all aspects. Its application in the educational field is increasing day after day and taking many forms according to its diverse applications which led to creating mobile learning concept. This mode of learning is considered as an extension of the electronic revolution in learning and distance education and will in its turn will bring change in the design of the teaching methods (Barbosa et al., 2010). It is worth mentioning that the Jordanian universities are pioneers in applying the latest technologies in education including the mobile learning at the regional level.

In order to develop education and its input, it is imperative for these universities to benefit from the advantages of this type of learning which saves time and effort for teachers and students, and enhances communication between them, in addition to the possibility to use it as a tool for making phone calls and for learning as well. In spite of all these advantages and these importance in education the use of mobile learning is still in its infancy and it still encounters several challenges and obstacles, whether technical in terms of the appropriateness of the educational content with the various types of the mobile phone devices, or material in terms of the high cost of the hardware, infrastructure necessary to establish these type of education.

This situation has led universities to pay attention to these obstacles and challenges and try to find solutions in order to prepare an appropriate environment for students learning and innovation through the use of the mobile technologies in education. Hence, this study is an attempt to identify the obstacles which encounter Jordanian universities student in using the mobile technology in education. This study answers the following questions:

1) What are the obstacles that the Jordanian universities students encounter in using the mobile phone in university education?

2) Are there statistically significant differences among the obstacles that the Jordanian universities student encounter attributed to the specialization (scientific, humanitarian)? 
3) Are there statistically significant differences among the obstacles that the Jordanian university students' encounter attributed to the experience in the use of the mobile phone (high, medium, low)?

\section{Aim of the Study}

This study aimed at identifying the obstacles that encounter the usage of the mobile phone in university education and finding out if there was correlation between the obstacles that hinder the usage of mobile phone in university education and the of student and the students experience in using the mobile phone in the learning process to offer suggestions and recommendations to take the proper decisions to overcome those obstacles.

\section{Significance of the Study}

This research importance lies in the importance of the mobile phone and its impact on university education, and its versality and diversity since it deals with important educational issues such as the obstacles which hinder its usage in education. Identifying the obstacles that encounter the use of the mobile phone provides data and information which the decision markers at universities and higher education institutions can benefit from such information. The study may provide the university officials with the obstacles which hinder the use of results mobile phones in university education. The study result may provide literature review with a valuable and scientific result about those obstacles. Lack of Arab studies which investigated the obstacles that hinder mobile phone usage.

\section{Limitation of the Study}

The results of the study can be generalized in the light of the following limitations:

1) The study was limited to the students of Al-Hashemieh, Al-Albayt, and AL Balq'a universities during the second semester of the academic year 2013/2014.

2) The study contained one questionnaire only that was prepared and developed by the researcher. The validity and reliability of this questionnaire were verified by common ways. Therefore, the validity of the findings is dependent on the validity of the instrument of the study.

3) The generalization of the findings of the study that comes outside its statistical population is limited to the extent of the similarity between the outside society and the current society.

4) The extent of the obstacles that the Jordanian universities' students encounter in using the mobile phone in university education is limited to the items included in the measuring instrument that is used in the study.

\section{Operational Definitions}

1) Mobile phone: a wireless mobile device regardless of its type, technology and usage.

2) Obstacles to the use of the mobile phone: Any factors adversely affect the use of the mobile phone through text messages, multimedia or social network in any place and at any time, whether in use among students and faculty members, or among students themselves in university education which results in reducing its use. Those obstacles can be measured or identified by students' responses to the items of the instrument of the study.

\section{Review of Related Literature}

Some researchers conducted a number of studies on the obstacles and challenges that the students encounter in their use of the mobile phone in education.

Mohamad, Maringe and Woollard (2012) conducted a study which aimed to examine the concept of change management through identifying the opportunities and challenges that face the application of mobile phones in the Malaysian schools, it also aimed at collecting the data from the educational experts in Malaysian and the UK. Their study used the evaluation methodology and interview as a tool for the study the results indicated in the domain at challenge that which face the application of mobile learning in education represented in the misuse of the multimedia messages (MMS), Bluetooth, the applied education policy, and privacy violation. A proposal was suggested to develop a system that enables parents to control their children's mobile phones so as to prevent misuse.

Saleem (2011) conducted a study that aimed to develop a knowledge based system which includes the advantages, characteristics and obstacles to mobile learning. Saleem used the descriptive analytical method of the literature review of mobile learning the results indicated three categories of the challenges the technical domain which includes, copy rights, the availability of the equipment ready for mobile learning, the extent to keep abreast of the development in this domain, short life of the battery, and the capacity of storage. The educational domain which includes evaluation of the learning process inside and outside the classroom, the problem of cheating among students, the technologies of the gap among the competencies of the students in 
using the equipment, the design of the educational content and methods of instruction, emergence of isolation among some students, lack of training in the use of mobile phones, in education. The third domain is the domain of general challenges which includes the high cost of the mobile phone devices, the absence of a clear strategy for mobile learning, the geographical borders, the students use of the mobile phone in non-educational purposes, the mobile phone devices are not strong and endurable enough and the need for a new infrastructure.

Shami (2009) conducted a study which aimed to identify the benefits of mobile learning and the challenges that Jadara university students encounter when using the mobile phone in their learning. The results indicated that the most important challenges were knowledge and the method of using mobile phones. The challenge of language and cost did not have a specialization impact. When the students were asked whether the mobile learning by using mobile phone was practical, $95 \%$ of the respondents stated it was practical, and $100 \%$ of the respondents recommended applying this system at the university.

Kenny et al. (2008) conducted a study that aimed to identify the status of the students and instructions use of the mobile phone usage and the challenges they face in Western Canada University. The study was applied by the students and the instructor of the third year nursing specialization. The result indicated that the respondent found it easy and comfortable to use the mobile phone in university education and they did not face any difficulty in using the wireless technology for educational purposes in spite of some challenges they faced at the beginning.

Macconath and Praul (2008) conducted a study which aimed to evaluate the methods using the mobile learning and the challenges that encounter its usage and its future in West Chester University in Pennsylvania. The sample consisted of (112) students who were given the opportunity to use mobile learning tools which were developed by Hot Lava Software for the purposes of the study. They designed a test for the purposes of the study and were distributed to the sample by mobile phones; internet and the personal digital assistants (42) students were selected to apply for the test via mobile phones and personal digital assistants, compared with the rest of the members of the sample who were selected by the traditional methods. The result indicated that there were statistical significant differences in test scores in favor of the students who applied for the exam via mobile phones who obtained higher grades and more knowledge of the instructional material.

Corlett et al. (2005) conducted a study in Birmingham University to identify the possibilities and the challenges of mobile learning that students encounter in the learning process when using the mobile phones in education. The students were provided with a set of wireless personal digital assistants for a semester for the purposes of the study. The respondents were able to adapt with the mobile learning technology and its challenges positively, during the period of the study. The results also indicated the problems the respondents faced were technical in nature, for example the respondents complained about the little storage capacity of the memory card of the mobile phones, in addition to the short life of the batteries of those devices and same the difficulties were faced by the respondents in dealing with the software in there devices.

Oliver (2005) conducted a study about the use of mobile learning by the students of the Australian University, the results indicated that the new students of the university encountered some difficulties in using the mobile learning technology and knew little about how it was used, meanwhile the older students (in higher year levels) and the graduates showed a wider use of mobile learning.

The review of the related literature showed that current mobile learning applications encounter many obstacles when used in education, similar to most technological applications in this field. The current study is similar to the previous studies in studying the obstacles which hinder using the mobile phone in education, this study dealt with variable that other studies did not cover study. Besides, this is one of the pioneer studies that dealt with this topic in the Arab environment.

\section{Method of the Study}

This study used the a descriptive method and the survey technique to investigate the obstacles that the Jordanian university students encounter in using the mobile phone in university education, and the effects of different variable on these obstacles.

\section{Sample of the Study}

The sample of the study included (363) male and female students from: Hashemite, Al-Albeyt, and Balq'a Applied Universities for the second semester in 2013/2014 who were chosen according to stratified random cluster method. Table (1) shows the distribution of the s sample according to the variables. 
Table 1. The distribution of study sample according to the variables

\begin{tabular}{lllllll}
\hline Variable & \multicolumn{2}{l}{ Specialization } & \multicolumn{3}{l}{$\begin{array}{l}\text { Experience in the use of } \\
\text { mobile phone }\end{array}$} & Total \\
\cline { 1 - 6 } & Scientific & humanistic & High & medium & low & \\
\cline { 2 - 6 } number & 129 & 234 & 111 & 221 & 31 & 363 \\
percent & $35.4 \%$ & $64.6 \%$ & $30.6 \%$ & $60.9 \%$ & $8.5 \%$ & $100 \%$ \\
\hline
\end{tabular}

\section{Study Instrument}

The data were gathered through a questionnaire, prepared by the researcher for the objective of the study after reviewing the educational literature related to this field. The instrument was divided into two parts: The first was personal data, and the second include the obstacles that the Jordanian university students encounter in using the mobile phone in university education, which contain (40) items in its final forms as a result of implementing the validity and reliability procedures. The instrument in its primary form consisted of (46) items $85 \%$ of arbiters advised the researcher to delete six of these items. This advice was adopted. The study instrument consisted of four domains:

First domain: obstacles related to the university "Administrative". Second domain: obstacles related to the student's "Personal-training". Third domain: obstacles related to the mobile "Technical". Fourth domain: obstacles related to using mobile in education.

\subsection{Validity of the Instrument}

To ensure that the content of the questionnaire is valid, it was handed to 14 specialists in the field of curricula, education, IT, and instructional technology from the Hashemite, Yarmouk, Jordanian, and Al Al-Bayt Universities. These specialists were requested to give their opinions about the extent of the appropriateness for each of the items for measuring the objective that it had been designed for, in addition to checking the correctness of the language and clarity of meaning. Some items were modified according to their suggestions, while some of the items that $80 \%$ of the arbiters suggested to be deleted were deleted. The instrument in its final form consists of 40 items with four domains.

\subsection{Reliability of the Instrument}

The coefficient for the reliability the study instrument was figured by calculating the reliability coefficient according to Cronbaukh Alfa for internal consistency, as the reliability coefficient was (0.83). This percentage was considered acceptable for the objective of scientific research and that it enjoyed reliability that allowed using it with a high degree of reliance. Table 2 shows the results.

Table 2. Internal consistency for the domain of the instrument and the instrument as a whole

\begin{tabular}{llclll}
\hline Domains & Domain 1 & Domain 2 & Domain 3 & Domain 4 & all \\
\hline Number of items & 10 & 13 & 7 & 10 & 40 \\
Reliability coefficient & 0.82 & 0.84 & 0.81 & 0.85 & 0.83 \\
\hline
\end{tabular}

\section{Statistical Procedures}

The descriptive analysis was used in the analysis of the study data. The means and the standard deviations of the sample were extracted for each of the items of the questionnaire. To answer the first question, means, the standard deviation were used, to answer the second question, means, the standard deviation, and t-test were used, to answer the third question, means, the standard deviation, and analysis of variance (ANOVA) were used for analyzing the data. The analysis was performed by using the software (SPSS).

\section{Study Variables}

The independent variables:

1) The specialization of the student, which includes two categories, a: Scientific b. Humanitarian.

2) Experience in the use of mobile phones which includes three levels a-High. b-Medium. c- Low.

The Dependent variable: the obstacles that hinder the students at the Jordanian universities to use the mobile phones in university education. The degree of these obstacles can be measured according to the following criteria 
a from : 1 to less than 2.33 obstacles at low degree level b. From: 2.33 to less than 3.66 (obstacle at medium degree level) c. From: 3.66 to 5 (obstacles at a high degree level).

\section{Results of the Study}

Results related to the first question: What obstacles do students at the Jordanian universities encounter in using the mobile phones in university education? The means and the standard deviations of the sample were extracted for each of the items of the questionnaire. These items were classified downward according to the means and standard deviations of the obstacles that faced the students in using mobile in university education. Table 3 shows the results.

Table 3. Means and std. Deviation of the obstacle items arranged in a descending order

\begin{tabular}{|c|c|c|c|c|}
\hline \multirow[t]{2}{*}{ No. } & \multirow[t]{2}{*}{ Subject } & Mean & Std. & $\begin{array}{l}\text { Item } \\
\text { Order }\end{array}$ \\
\hline & & \multicolumn{3}{|c|}{ Deviation. } \\
\hline 19 & $\begin{array}{l}\text { Lack of information about mobile phone services in the educational } \\
\text { purposes. }\end{array}$ & 4.2 & 0.942 & 1 \\
\hline 31 & Lack of funding to employ a mobile phone in education. & 4.18 & 0.942 & 2 \\
\hline 11 & $\begin{array}{l}\text { Restricting mobile phone use to social and entertainment purposes } \\
\text { which distract the student from using the mobile phones for } \\
\text { educational purposes. }\end{array}$ & 4.13 & 1.005 & 3 \\
\hline 30 & $\begin{array}{l}\text { The high prices of some of the network services limits the use of the } \\
\text { mobile phone in education }\end{array}$ & 4.12 & 1.036 & 4 \\
\hline 17 & $\begin{array}{l}\text { The university doesn't holding training courses for students to } \\
\text { explain the use of the mobile phone in education. }\end{array}$ & 4.1 & 1.043 & 5 \\
\hline 16 & Misuse of mobile phone limits its use in educational purposes. & 4.07 & 1.043 & 6 \\
\hline 9 & $\begin{array}{l}\text { The university doesn't holding training courses for faculty members } \\
\text { in the field of using the mobile phone in the university teaching. }\end{array}$ & 4.06 & 1.015 & 7 \\
\hline 14 & High cost of using mobile phone in educational purposes. & 4.04 & 1.045 & 8 \\
\hline 22 & $\begin{array}{l}\text { Entertainments services in the mobile phone consume time of the } \\
\text { students and reduce the use it in the university education. }\end{array}$ & 4.04 & 1.07 & 9 \\
\hline 24 & $\begin{array}{l}\text { The small screen size of mobile phone hinders its use in educational } \\
\text { purposes. }\end{array}$ & 4.03 & 1.074 & 10 \\
\hline 38 & $\begin{array}{l}\text { Tendency of students to use the mobile phone is different way which } \\
\text { is planned from the faculty members }\end{array}$ & 4.03 & 1.043 & 11 \\
\hline 15 & The mobile phone is not available for all students. & 4.01 & 1.114 & 12 \\
\hline 8 & $\begin{array}{l}\text { University does not provide educational sources to provide it to the } \\
\text { students via mobile phone. }\end{array}$ & 3.95 & 0.999 & 13 \\
\hline 10 & $\begin{array}{l}\text { The large teaching loads for the faculty members prevent the use of a } \\
\text { mobile phone. }\end{array}$ & 3.93 & 1.058 & 14 \\
\hline 25 & $\begin{array}{l}\text { Disconnection as the result of the weakness of the mobile network } \\
\text { hinders the use of the mobile phone in education. }\end{array}$ & 3.93 & 1.025 & 15 \\
\hline 1 & $\begin{array}{l}\text { The huge number of students at the university makes it difficult to } \\
\text { connect these students with the university through mobile phones. }\end{array}$ & 3.92 & 1.178 & 16 \\
\hline 2 & $\begin{array}{l}\text { Universities don't care to enter the mobile phone in university } \\
\text { education. }\end{array}$ & 3.92 & 0.951 & 17 \\
\hline 26 & $\begin{array}{l}\text { The lack of educational software used to connect with mobile } \\
\text { phones. }\end{array}$ & 3.92 & 1.044 & 18 \\
\hline 12 & $\begin{array}{l}\text { The ignorance of the students of the importance of the mobile phone } \\
\text { in education. }\end{array}$ & 3.91 & 1.057 & 19 \\
\hline 28 & $\begin{array}{l}\text { Mobile phone memory capacity prevents its use for the educational } \\
\text { purposes. }\end{array}$ & 3.91 & 1.16 & 20 \\
\hline 40 & $\begin{array}{l}\text { The students have low experience in the mobile phone uses in the } \\
\text { educational purposes. }\end{array}$ & 3.90 & 1.158 & 21 \\
\hline 27 & $\begin{array}{l}\text { The lack of technical services in creating and operating mobile } \\
\text { phones for the field of the education. }\end{array}$ & 3.89 & 1.032 & 22 \\
\hline
\end{tabular}




\begin{tabular}{|c|c|c|c|c|}
\hline 29 & $\begin{array}{l}\text { The coverage of the networks is not available in all school districts } \\
\text { which preclude their use in educational purposes. }\end{array}$ & 3.89 & 1.104 & 23 \\
\hline 3 & $\begin{array}{l}\text { Increase the financial burden of the university makes it difficult to } \\
\text { use a mobile phone in education }\end{array}$ & 3.88 & 1.068 & 24 \\
\hline 5 & $\begin{array}{l}\text { The faculty members don't take care of using the mobile phone in } \\
\text { education. }\end{array}$ & 3.88 & 1.0102 & 25 \\
\hline 18 & $\begin{array}{l}\text { The Students are not convinced of the importance of the mobile } \\
\text { phone in education. }\end{array}$ & 3.88 & 1.099 & 26 \\
\hline 13 & $\begin{array}{l}\text { The large number of duties required from the student for curriculum } \\
\text { and courses prevent the use of a mobile phone in educational } \\
\text { purposes. }\end{array}$ & 3.87 & 1.064 & 27 \\
\hline 6 & $\begin{array}{l}\text { The lack of the possibility of sending homework duties to the faculty } \\
\text { member via mobile phone. }\end{array}$ & 3.86 & 1.132 & 28 \\
\hline 39 & $\begin{array}{l}\text { Inability to organize information that is obtained through a mobile } \\
\text { phone. }\end{array}$ & 3.86 & 1.037 & 29 \\
\hline 32 & $\begin{array}{l}\text { The difficulty to insert this technology in the curriculum and } \\
\text { teaching courses. }\end{array}$ & 3.85 & 1.018 & 30 \\
\hline 34 & $\begin{array}{l}\text { Lack of confidence in the correctness of the information and data } \\
\text { that are sent via mobile phone. }\end{array}$ & 3.84 & 1.102 & 31 \\
\hline 33 & $\begin{array}{l}\text { The absence of the field to employ what is obtained from the } \\
\text { information in the educational purposes. }\end{array}$ & 3.82 & 0.993 & 32 \\
\hline 23 & $\begin{array}{l}\text { The difficulty of communication between students and teacher } \\
\text { through a mobile phone. }\end{array}$ & 3.81 & 1.166 & 33 \\
\hline 35 & $\begin{array}{l}\text { The difficulty of preparing educational material using a mobile } \\
\text { phone. }\end{array}$ & 3.81 & 1.071 & 34 \\
\hline 7 & $\begin{array}{l}\text { The university administrator and the faculty members doesn't } \\
\text { convinced of using a mobile phone in the educational purposes of } \\
\text { teaching staff and management. }\end{array}$ & 3.77 & 1.084 & 35 \\
\hline 21 & $\begin{array}{l}\text { There is no motivation to faculty members to use this technology in } \\
\text { education. }\end{array}$ & 3.72 & 1.09 & 36 \\
\hline 37 & $\begin{array}{l}\text { The weakness of students' motivation to learn when using a mobile } \\
\text { phone. }\end{array}$ & 3.69 & 1.172 & 37 \\
\hline 4 & $\begin{array}{l}\text { University does not encourage faculty members to introduce modern } \\
\text { patterns in education, such as using a mobile phone. }\end{array}$ & 3.67 & 1.121 & 38 \\
\hline 36 & $\begin{array}{l}\text { The lack of possibility to link of educational outputs via mobile } \\
\text { phone with the necessity of the labor market. }\end{array}$ & 3.66 & 1.077 & 39 \\
\hline 20 & $\begin{array}{l}\text { Lack of expected benefits from the use of mobile phone in } \\
\text { educational purnoses. }\end{array}$ & 3.62 & 1.034 & 40 \\
\hline All & & 3.90 & 1.064 & \\
\hline
\end{tabular}

The table 3 shows that all the items as a whole formed high degree obstacles in the use of mobiles phone in the educational process, where the mean of the instrument as a whole (3.90), and one item formed medium degree with mean (3.62), which item (Lack of expected benefits from the use of mobile phone in educational purposes.) and its totaled items that got mean (4) and up (12) item, and the item is the highest (Lack of information about mobile phone services in the educational purposes) with mean (4.2), while the item number (6) (The mobile phone is not available for all students) with mean (4.01), has a total of item which ranged from the mean between (3.5) and (4) (28) item, where the item (University does not provide educational sources to provide it to the students via mobile phone) with mean (3.95). As for the domains table (4) shows the results. 
Table 4. Means and std. Deviation of the 0bstacles for all domains arranged in a descending order

\begin{tabular}{llll}
\hline Domain No. & Mean & Std. Deviation. & Domain Order \\
\hline Domain 2 & 3.95 & 1.059 & 4 \\
Domain 3 & 3.90 & 1.064 & 3 \\
Domain 1 & 3.88 & 1.0708 & 2 \\
Domain 4 & 3.86 & 1.061 & 1 \\
All domains & 3.90 & 1.064 & \\
\hline
\end{tabular}

Table 4 shows that all domains formed high degree obstacles in the use of mobile phone in education, the second domain came in the first, with a mean of (3.95), followed by the domain of obstacles that relate to the mobile phone (technical) with a mean (3.90), then the domain of obstacles that relate to the university (administrative) with a mean of (3.88), and came in the final domain of obstacles that are related to the employment of a mobile phone in education with a mean (3.86).

The second question: Are there statistically significant differences among the obstacles that the Jordanian university students' encounter attributed to the specialization (Scientific, Humanitarian)?

To know whether there were differences among these means according to the specialization veriable, $t$-test was conducted. Table (5) shows the results.

Table 5. The means and Std. Deviation and t-test of the obstacles according to the Specialization

\begin{tabular}{lllllll}
\hline Obstacles & Specialization & No. & Means & $\begin{array}{l}\text { Std. } \\
\text { Deviation. }\end{array}$ & $\begin{array}{l}\text { (T) } \\
\text { Value }\end{array}$ & $\begin{array}{l}\text { Significant } \\
\text { level }\end{array}$ \\
\hline Obstacles domain 1 & Scientific & 129 & 3.82 & 0.724 & $1.271-$ & 0.24 \\
& Human & 234 & 3.92 & 0.666 & $1.241-$ & \\
Obstacles domain 2 & Scientific & 129 & 3.90 & 0.707 & $1.134-$ & \\
& Human & 234 & 3.98 & 0.574 & $1.069-$ & $0.005^{*}$ \\
Obstacles domain 3 & Scientific & 129 & 3.87 & 0.753 & $1.566-$ & \\
& Human & 234 & 4.00 & 0.715 & $1.542-$ & 0.390 \\
Obstacles domain 4 & Scientific & 129 & 3.77 & 0.700 & $1.901-$ & \\
& Human & 234 & 3.91 & 0.680 & $1.886-$ & 0.458 \\
All & Scientific & 129 & 3.85 & 0.624 & $1.724-$ & \\
& Human & 234 & 3.95 & 0.530 & $1.645-$ & 0.058 \\
\hline
\end{tabular}

The table 5 shows that there were statistically significant differences at the level $(\alpha \leq 0.05)$ in the field of obstacles related to the student (personal-training) due to the variable of specialization, in favor of humanitarian specialization. The mean of the scientific specialization was (3.90) and the mean of humanitarian specialization was (3.98), but there are no statistically significant differences for another domains and the instrument as a whole.

The third question: Are there statistically significant differences among the obstacles that the Jordanian university students' encounter attributed to the experience in the use of the mobile phone (high, medium, low)? To know whether there were differences among these means according to the experience in the use of the mobile phone variable. The means and Std. Deviation of the domain for the obstacles was conducted. Table 6 shows the results. 
Table 6. The means and Std. Deviation of the domain for the obstacles according to the experience

\begin{tabular}{lllll}
\hline Domain /obstacles & Experience & No. & Means & Std. Deviation \\
\hline Domain 1 & High & 111 & 4.00 & 0.689 \\
& Medium & 221 & 3.84 & 0.667 \\
& Few & 31 & 3.80 & 0.798 \\
Domain 2 & Total & 363 & 3.88 & 0.688 \\
& High & 111 & 3.95 & 0.662 \\
& Medium & 221 & 3.94 & 0.586 \\
Domain 3 & Few & 31 & 4.05 & 0.757 \\
& Total & 363 & 3.95 & 0.625 \\
& High & 111 & 4.02 & 0.739 \\
Domain 4 & Medium & 221 & 3.91 & 0.699 \\
& Few & 31 & 4.06 & 0.893 \\
& Total & 363 & 3.96 & 0.730 \\
& High & 111 & 3.93 & 0.740 \\
& Medium & 221 & 3.81 & 0.646 \\
& Few & 31 & 3.97 & 0.787 \\
& Total & 363 & 3.86 & 0.689 \\
& High & 111 & 3.97 & 0.590 \\
& Medium & 221 & 3.88 & 0.535 \\
& Few & 31 & 3.97 & 0.693 \\
& Total & 363 & 3.91 & 0.567 \\
\hline
\end{tabular}

Table 6 shows that there were differences among the means. To find out whether there were significant differences at level $(\alpha \leq 0.05)$ according to the experience in using mobile phone between these means ANOVA was conducted. Table 7 shows the results.

Table 7. The results of ANOVA according to the experience in using mobile phone

\begin{tabular}{lllllll}
\hline $\begin{array}{l}\text { Domain } \\
\text { obstacles }\end{array}$ & Source & $\begin{array}{l}\text { Sum of } \\
\text { Squares }\end{array}$ & DF & $\begin{array}{l}\text { Mean } \\
\text { Squares }\end{array}$ & F Value & Sig. \\
\hline Domain 1 & Experience & 2.168 & 2 & 1.084 & 2.307 & 0.10 \\
& Error & 169.133 & 360 & 0.470 & & 1 \\
& Total & 171.301 & 362 & & & \\
Domain 2 & Experience & 0.333 & 2 & 0.166 & 1.284 & 0.65 \\
& Error & 140.874 & 360 & 0.391 & & 4 \\
& Total & 141.206 & 362 & & & \\
Domain 3 & Experience & 1.368 & 2 & 0.684 & 1.284 & 0.27 \\
& Error & 191.690 & 360 & 0.532 & & 8 \\
& Total & 193.058 & 362 & & & \\
Domain 4 & Experience & 1.450 & 2 & 0.725 & 1.531 & 0.21 \\
& Error & 170.550 & 360 & 0.474 & & 8 \\
& Total & 172.000 & 362 & & & \\
Domain as & Experience & 0.773 & 2 & 0.387 & 1.204 & 0.30 \\
a whole & Error & 115.610 & 360 & 0.321 & & 1 \\
& Total & 116.383 & 362 & & & \\
\hline
\end{tabular}


Table 7 shows that there are no statistically significant differences at $(\alpha \leq 0.05)$ attributed to experience in using mobile phone for the all domain and the instrument as a whole.

\section{Discussion of the Results}

As for the result of the first question regarding the obstacles that hinder the students at the Jordanian universities to use mobile phones in university education, the results show that all the items of the instrument (except one item) were perceived by the students as high obstacles. This result could be attributed to the recent use of this instructional method in university education at the Jordanian universities. This may explain the lack of knowledge of students of the use of mobile phones in education and their low experience in this field, or could be attributed to the high prices of mobile technology services and its software, or the decrease in finance, or the misuse of this service, and restricting its use to social and entertainment purposes which distract the student from using the mobile phone for educational purposes, and university education. In addition, the small size of the mobile phone screen, the low capacity of the memory and the lack of sufficient amount of developed mobile phones may hinder the use of mobile phones in university education.

Besides, the faculty members do not care about such mode of instruction due to their heavy academic loads, faculty members and students are in need of training courses on how to use such technology in education. This result is consistent with the result of the study Mohamad, Maringe \& Woollard (2012) which indicated that the most important obstacle which hinder using the mobile phone in university education was misusing the mobile phones, and it is also consistent with the results of the study conducted by Oliver (2005) which indicated that the new students encountered more difficulties in using the mobile phones in education than the older ones.

The results of this study are inconsistent with the results of the study conducted by Shami (2009) which indicated that the cost of the mobile phone had not impact on its use, The results of this study are also inconsistent with the results of the study conducted by Kenny et al. (2008) which indicated that the respondents found it easy to use the mobile phone and to apply it in education. And, they did not face any difficulty in using and applying it in education.

The reason for the results is that the universities do not give the opportunity for the students to use the mobile phone in university education. In addition, the universities do not encourage faculty members to introduce such modern techniques in higher education due to the lack of financial support. Indeed, the main obstacle of using e-learning according to the study of (Mohammad et al, 2006) was financial issue. However, the universities have started recently to give more attention to the e-learning technology.

The result of the second question showed statistically significant differences, in the domain related to students' specialization in favor of human sciences specialists. This can be attributed to the fact that the students of scientific discipline employ the internet electronic learning, mobile and other technological tools and inventions because of the nature of their specializations, whereas their colleagues who study human and social sciences, depend less on technology. The absence of significant differences in other domains is the result of the same conditions and circumstances all students share. This result is in agreement with the results reached in (Kenny et al, 2008) study which showed that students of scientific disciplines faced no obstacles in using mobiles.

The result of the third question showed that there were no significant differences in this regard. This can be attributed to the intensive use of the mobile by students in many aspects of their lives regardless of their experience in this field. So there were no differences in the obstacles all students face in their use of the mobile as a learning tool. This result is in agreement with the results of a study done by Oliver (2005) which indicated that all students coped with the use of the mobile irrespective of their experiences.

\section{Recommendations}

1) Encouraging students to use mobile phones in university education to acquire more experience and enhance their interaction with this new mode of instruction.

2) Integrating the mobile use into the university curriculum by blending this technology with curriculum text books and syllabi.

3) Holding training courses for students and faculty members in using the mobile phone in university education and to acquire more experience in this field.

4) More government financial support should be provided to the Jordanian universities to enable them to adapt and use the latest technology such the mobile phone in education.

5) Faculty members are invited to conduct further research studies on mobile phone use in university education which may deal with other variables, such as the accumulative grade point average, the relation between the 
students' attitudes toward mobile phone use in education and the ability to use it, and the academic level of the students.

6) Further research studies are recommended to identify the obstacles which encounter the mobile phone usage in university education from the perspectives of the faculty members.

\section{References}

Barbosa, J., Reinhard, N., Saccol, A., \& Schlemmer, E. (2010). M-learning in practice: A training experience with IT professionals. Journal of Information Systems and Technology Management, 7(2), 261-280. http://dx.doi.org/10.4301/S1807-17752010000200002

Bassiouni, A. H. (2007). Mobile e-learning and education (Scientific Books Library) (1st ed.). Cairo. Egypt.

Bin Hashem, A., W. A. W., \& Ahmad, R. (2010). Mobile Learning Implementation: Students' Perception in UTP. World Academy of Science, Engineering and Technology, 62, 816-819.

Chen, J., \& Kinshuk, M. (2003). Mobile Technology in Educational Services. Advanced Learning Technologies Research Center, Massey University, Palmerstone, North, New Zealand.

Corlett, D., Sharples, M., Bull, S., \& Chan, T. (2005). Evaluation of a mobile learning organizer for university

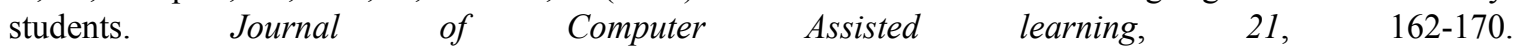
http://dx.doi.org/10.1111/j.1365-2729.2005.00124.x

Csete, J., Wong, Y. H., \& Vogel, D. (2004). Mobile devices in and out of the classroom. In Cantoni, \& Mc Laughlin (Eds.), Proceedings of ED-Media 2004. Lugano, Switzerland.

Dahshan, J., \& Younis M. (2009, April 29). Education by Mobile Learning “new formula for distance learning”. Paper presented to the first scientific symposium of the Department of Comparative Education and Educational Management, College of Education-University of Kafr El-Sheikh under the title of "higher education systems the default".

Dunn, J. (2012). 10 Big (But never discussed) problems with mobile Learning. Edudemic. Retrieved July 5, 2014, from http://edudemic.com/2012/09/10-big-but-never-discussed-problems-with-mobile-learning/

Ganci, J. (2010). Mobile Learning: Obstacles and Solutions. Learning Solution Magazine, 437.

Hamamy, M. (2006). Mobile learning a new phase of e-learning. M-Learning-a new stage of E-Learning (The Turkish Online Journal of Educational Technology). Journal of Informatics-Technology in Education. Retrieved August 6, 2006, from http://infomag.news.sy/index.php?inc=issues/showarticle\&issueenb $=6 \& \mathrm{id}=70$

Hayes, P., Joyce, D., \& Pathak, P. (2004). Ubiquitous learning-an application of mobile technology in education. In Cantoni, \& McLaughlin (Eds.), Proceedings of ED-Media 2004. Lugano, Switzerland.

Journal-informatics technology in education, 6. (2006, August). Retrieved from http://infomag.news.sy/index.php?inc $=$ issues/showarticle \&issueen $=6 \& \mathrm{id}=70$

Kenny, R. F., Park, C. L., Burton, P. A., \& Meires, J. (2008). The feasibility of using mobile devices in nursing practice education. North Island College, 2300 Rayan Road, Courtenay, B. C., Canada.

Mcconatha, D., \& Praul, M. (2008). Mobile Learning in Higher Education: An Empirical Assessment of a New Educational Tool. The Turkish Online Journal of Educational Technology, 7(3), 15-21.

Mohamad, M., Maringe, F., \& Woolard, J. (2012). Mobile Learning in Malaysian Schools: Opportunities and Challenges of introducing teaching through mobile phones. International Journal for e-Learning Security, 2(1/2), 133-137.

Mohammad, J., Al-Sheikh. A., \& Atyeh, A. (2006). The obstacles of using e-learning from the HU students' perspectives. Journal of educational \& psychological sciences, 7(4), 184-206.

Oliver, B. (2005). Australian University Students' Use of and Attitudes towards Mobile Learning Technologies. IADIS. Industrial Conference Mobile Learning, 193-197.

Saleem, T. A. (2011). Mobile Learning Technology: A new step in e-learning. Journal of Theoretical and Applied Information Technology, 34(2), 125-137.

Salem, A. (2006). Mobile learning ... A new vision for learning using wireless technologies. Working paper submitted to the Scientific Conference of the eighteenth of the Egyptian Society of curricula and teaching methods in the period from July 25 to $26,2006$. 
Salem, A. (2004). Education and e-learning technology (Rasheed library) (1st ed.). Reyad.

Shami, A. (2009). Education via the mobile application concept and its importance and challenges to the students of Jadara University. Paper presented to the Conference of informatics and Arab issues of development, 28 to 29 March 2009.

\section{Copyrights}

Copyright for this article is retained by the author(s), with first publication rights granted to the journal.

This is an open-access article distributed under the terms and conditions of the Creative Commons Attribution license (http://creativecommons.org/licenses/by/3.0/). 